\title{
Resources About Donald A.B. Lindberg M.D.
}

\author{
Robert A. LOGAN Ph.D. ${ }^{1}$ \\ U.S. National Library of Medicine (retired)
}

\begin{abstract}
Keywords. Donald A.B. Lindberg M.D., U.S. National Library of Medicine,
\end{abstract} History of the U.S. National Library of Medicine

\section{Introduction}

This section provides a selected, partially annotated guide to Internet-based and other resources about Donald A. B. Lindberg M.D.'s contributions and career. The criteria for selections include an active URL, a distinctive approach, and recommendations from some of the book's contributors. Its sections provide some tributes written after Dr. Lindberg's death, selected obituaries, tributes delivered when Dr. Lindberg's retired from the U.S. National Library of Medicine (NLM), links to the Native Voices exhibition, other resources about Dr. Lindberg's career and contributions, manuscripts authored by Dr. Lindberg, manuscripts about biomedical informatics' progress coauthored by Dr. Lindberg, and links to NLM annual reports written during Dr. Lindberg's helm.

\section{Selected Tributes and Obituaries Written after Dr. Lindberg's Death in August 2019}

Kohane I, Berg JM. Donald A.B. Lindberg (1933-2019). Science. 366:6461, p. 37. DOI: 10.1126/science.aaz3644.

https://science.sciencemag.org/content/366/6461/37

This tribute in Science provides information about Dr. Lindberg's biomedical contributions and suggests he was an 'unsung hero of medical research and science.'

Humphreys BL, Rosenbloom M. Donald A.B. Lindberg, MD, honorary MLA member. J Med Libr Assoc. 2020, Apr:108(2): 314-317.

https://www.ncbi.nlm.nih.gov/pmc/articles/PMC7069826/;

http://jmla.mlanet.org/ojs/jmla/article/view/878/1083

Humphreys was NLM's Deputy Director from 2005-2015 and NLM's acting director from 2015-2016. Humphreys is a co-editor of the current book.

\footnotetext{
${ }^{1}$ Corresponding author: logrob@gmail.com
} 
Kulikowski CM. Donald A.B. Lindberg's historical impact: catalyzing the revolution in biomedical and healthcare knowledge through informatics with free, open dissemination worldwide. Yearb Med Inform 2020. P. 203-207. http://dx.doi.org/10/1055/s-00401701972

Dr. Kulikowski, who is a contributor to the current book, summarizes Dr. Lindberg's contributions to biomedical informatics and healthcare knowledge.

McCray AT, Haux R, van Bemmel JH. In memorium: Donald A. B. Lindberg (19332019). Methods Inf Med 2019: 58:107-108. https://doi.org/ 10.1055/s-0039-3400249.

This tribute provides a brief overview of Dr. Lindberg's contributions to medical libraries, science, biomedicine, and biomedical informatics. Dr. McCray was the director of the Lister Hill National Center for Biomedical Communications and worked with Dr. Lindberg at NLM for almost two decades. Dr. van Bemmel is a contributor to the current book.

Logan RA. Remembering Don Lindberg: a transformative leader. Health Affairs Blog. Sept. 27, 2019. https://www.healthaffairs.org/do/10.1377/hblog20190923.307979/full/

This tribute focuses on Dr. Lindberg's character and leadership qualities. Logan was a member of NLM's senior staff from 2006-2018 and is one of the current book's coeditors.

Seelye KQ. Dr. Donald Lindberg, 85, dies: opened medical research to the world. New York Times. September 2, 2019. https://www.nytimes.com/2019/09/02/obituaries/drdonald-lindberg-dead.html? searchResultPosition=1

The New York Times' obituary is based on interviews with some colleagues and members of the Lindberg family. It is reprinted with an introduction from Elliot Siegel (one of the current book's co-editors) in: Information Services \& Use 39 (2019) 123126. DOI:10.3233/ISU-190058.

Donald A.B. Lindberg, pioneer in medical informatics, died Aug. 17, 2019. Columbia Missourian. August 21, 2019. https://www.columbiamissourian.com/obituaries/ family_obituary/donald-a-b-lindberg-pioneer-in-medical-informatics-died-aug-172019/article_022ee246-c45b-11e9-964f-47c2551d9b1c.html

This is a conventional obituary about Dr. Lindberg's life and career. The Columbia Missourian is a daily metropolitan newspaper published by the University of MissouriColumbia School of Journalism. Dr. Lindberg lived in Columbia, MO and was a faculty member at the University of Missouri-Columbia School of Medicine for almost two decades.

\section{Some Tributes from Dr. Lindberg's NLM Retirement in March 2015}

https://www.nlm.nih.gov/news/DrLindbergRetirementSymposiumVideos.html\#fairwin ds title

Includes one hour and 45 minutes of video tributes to Dr. Lindberg. The videos were prepared by NLM for Dr. Lindberg's retirement ceremony on March 30, 2015. 
https://collections.nlm.nih.gov/catalog/nlm:nlmuid-101629547-vid

Provides Dr. Lindberg's speech at the ceremony where he was sworn-in as NLM's director on October 11, 1984. It outlines part of the path and steps he would take for the next 31 years.

https://wayback.archive-it.org/org-350/20180911191348/https://www.nlm.nih.gov/ news/bor_resolution_lindberg_2015.html

This 2015 resolution from the NLM Board of Regents outlines some of Dr. Lindberg's contributions to NLM and biomedical informatics.

https://infocus.nlm.nih.gov/2015/04/14/the-end-of-an-era-director-lindberg-retiresafter-31-years-leading-nlm/

NLM's In Focus report on Dr. Lindberg's retirement ceremony.

\section{Links to Native Voices: Native People's Concepts of Health and Illness}

https://www.nlm.nih.gov/nativevoices/index.html

This is the home page of Native Voices, which included exhibitions, websites, video interviews, art, resources, and much more. The development and contributions of Native Voices are described in two chapters in section four of the current book.

https://nvinterviews.nlm.nih.gov/interviews//

Dr. Lindberg interviewed more than 100 Native American, Alaska Native, and Native Hawaiian physicians, other health care providers, faculty, traditional healers, clergy, hospital/organizational administrators, medical and public health students, political leaders, and others, for the Native Voices exhibition. The interviews are available here.

\section{Links to Other Written Resources about Dr. Lindberg's Career and Contributions}

https://lhncbc.nlm.nih.gov/system/files/Medical-Informatics-Pioneers_OralHistory_DONALD-LINDBERG_2015-09-04_web.pdf

This oral history about Dr. Lindberg was prepared by NLM's Lister Hill National Center for Biomedical Communication in 2005.

https://www.mlanet.org/blog/lindberg-donald-ab-md

Provides a brief oral history of Dr. Lindberg's tenure at NLM from the Medical Library Association. It was prepared in 2015.

https://en.wikipedia.org/wiki/Donald_A._B._Lindberg

This accesses Wikipedia's page about Dr. Lindberg.

Wortsman P. A digital pioneer at the National Library of Medicine: Donald A.B. Lindberg, 58'. In: Wortsman P. The caring heirs of Doctor Samuel Bard: profiles of 
selected distinguished graduates of Columbia University Vagelos College of Physicians and Surgeons. New York: Columbia University Press; 2019. p. 239-244.

This profile covers some aspects of Dr. Lindberg's career, influences, and contributions. It is included in a book of tributes to Samuel Bard M.D., Columbia University, who was one of Dr. Lindberg's mentors.

Smith KA. Laws, leaders, and legends of the modern National Library of Medicine. J Med Libr Assoc. 2008 Apr;96(2):121-33. DOI: 10.3163/1536-5050.96.2.121. PMID: 18379667; PMCID: PMC2268223. https://www.ncbi.nlm.nih.gov/pmc/articles/ PMC2268223/

This paper explains how four Congressional actions from 1956 to 1988 impacted NLM's growth and development. While the paper covers actions prior to Dr. Lindberg's tenure as NLM's director, it notes how Dr. Lindberg envisioned a new role for NLM in advancing biomedical informatics when he became NLM's director in 1984. The latter resulted a 1986 long range plan that provided a foundation for the congressional legislation which created the National Center for Biotechnology Information (NCBI). It is written by Kent Smith, NLM's Deputy Director from 1979-2004, who is an author of a chapter in the current book.

\section{Manuscripts Authored by Dr. Lindberg}

There are two ways to access the research and writings of Dr. Lindberg in PubMed. PubMed, developed by NCBI, became the interface to NLM's MEDLINE database and other journal and book chapter citations while Dr. Lindberg was NLM's director. NCBI is a division within NLM.

https://pubmed.ncbi.nlm.nih.gov/?term=Lindberg\%20DA

Or, type 'Lindberg DA' in the search box on PubMed's home page: https://pubmed.ncbi.nlm.nih.gov

https://wayback.archive-it.org/org-350/20190104163823/

https://www.nlm.nih.gov/pubs/staffpubs/od/dablbib.html

Provides an archive of some of Dr. Lindberg's work at NLM.

https://scholar.google.com/

Dr. Lindberg's writing also is accessible through Google Scholar. Type 'Donald AB Lindberg' in the search box.

\section{Summaries of Biomedical Informatics Progress and Access to Biomedical Information: Co-written by Dr. Lindberg During his Tenure as NLM's director}

https://www.ncbi.nlm.nih.gov/pmc/articles/PMC2441483/

https://www.ncbi.nlm.nih.gov/pmc/articles/PMC5171500/

These articles, co-authored by Dr. Lindberg and Betsy Humphreys in 2008 and 2016, provide overviews of the progress in biomedical informatics. 


\section{Links to NLM Reports during Dr. Lindberg's Tenure as Director}

NLM annual reports from 1984-1996.

https://www.nlm.nih.gov/hmd/manuscripts/nlmarchives/annualreport.html

These reports cover the first 12 years Dr. Lindberg was NLM's director.

NLM annual reports from 1997-2015.

https://www.nlm.nih.gov/pubs/reports.html

These reports cover the 18 additional years Dr. Lindberg was NLM's director. The link also provides access to diverse NLM reports, which include several written during Dr. Lindberg's tenure.

https://www.nlm.nih.gov/od/bor/bor.html

Minutes of NLM's Board of Regents meetings during the years Dr. Lindberg was NLM's director (1984-2015).

\section{NLM News}

https://www.google.com/books/edition/News/TVYf-

ohKmgMC?hl=en\&kptab=editions

Digitized versions of NLMNews, which cover a range of information about some of NLM's grant programs, outreach activities, developments at NCBI, milestones related to NLM services for consumers, and other initiatives during Dr. Lindberg's helm.

\section{Acknowledgements}

The thoughtful contributions of Betsy Humphreys, Elliot Siegel, Randy Miller, Mary Lindberg, Kent Smith, and Fred Wood are gratefully acknowledged. 